\title{
A Conceptual Definition of Vocational Rehabilitation Based on the ICF: Building a Shared Global Model
}

\author{
Reuben Escorpizo $\cdot$ Michiel F. Reneman • Jan Ekholm $\cdot$ Julie Fritz $\cdot$ \\ Terry Krupa · Sven-Uno Marnetoft · Claude E. Maroun · Julietta Rodriguez Guzman • \\ Yoshiko Suzuki · Gerold Stucki · Chetwyn C. H. Chan
}

Published online: 17 February 2011

(C) Springer Science+Business Media, LLC 2011

\begin{abstract}
Background The International Classification of Functioning, Disability and Health (ICF) is a conceptual framework and classification system by the World Health Organization (WHO) to understand functioning. The objective of this discussion paper is to offer a conceptual definition for vocational rehabilitation (VR) based on the ICF. Method We presented the ICF as a model for application in VR and the rationale for the integration of the ICF. We also briefly reviewed other work disability models. Results Five essential elements of foci were found towards a conceptual definition of VR: an engagement or re-engagement to work, along a work continuum, involved health conditions or
\end{abstract}

R. Escorpizo $(\bowtie) \cdot$ G. Stucki

Swiss Paraplegic Research (SPF), Guido A. Zäch Str. 4,

6207 Nottwil, Switzerland

e-mail: reuben.escorpizo@paranet.ch

R. Escorpizo - G. Stucki

ICF Research Branch in Cooperation with the WHO

Collaborating Centre for the Family of International

Classifications in Germany (at DIMDI), Nottwil, Switzerland

R. Escorpizo · G. Stucki

Department of Health Sciences and Health Policy,

University of Lucerne, and at SPF, Nottwil, Switzerland

M. F. Reneman

Center for Rehabilitation and Department of Rehabilitation

Medicine, University Medical Center Groningen,

Groningen/Haren, The Netherlands

J. Ekholm

Department of Clinical Sciences DS, Karolinska Institutet,

Stockholm, Sweden

J. Fritz

Department of Physical Therapy, University of Utah College

of Health, Salt Lake City, UT, USA events leading to work disability, patient-centered and evidence-based, and is multi-professional or multidisciplinary. Conclusions VR refers to a multi-professional approach that is provided to individuals of working age with health-related impairments, limitations, or restrictions with work functioning and whose primary aim is to optimize work participation. We propose that the ICF and VR interface be explored further using empirical and qualitative works and encouraging stakeholders' participation.

Keywords ICF - Vocational rehabilitation - Employment . Work $\cdot$ Concept formation $\cdot$ Theory

\section{T. Krupa}

School of Rehabilitation Therapy, Queen's University, Kingston, ON, Canada

\section{S.-U. Marnetoft}

Department of Health Sciences, Mid Sweden University,

Östersund, Sweden

\section{E. Maroun}

American University of Beirut Medical Center, Beirut, Lebanon

J. R. Guzman

Occupational Health Graduate Program, Faculty of Medicine, Universidad El Bosque, Bogota, Colombia

Y. Suzuki

Tokyo Metropolitan Rehabilitation Center for the Physically and Intellectually Disabled, Mejiro University, Tokyo, Japan

C. C. H. Chan

Department of Rehabilitation Sciences, The Hong Kong

Polytechnic University, Hong Kong, China 


\section{Introduction}

In the work disability arena, the International Labour Organization (ILO) strives to promote decent work and livelihood, job-related security and living standards in all countries. Further, the ILO advocates for rights at work, to encourage opportunities for decent employment, to enhance social protection and to strengthen dialogue on work-related issues [1]. In 2007, the World Health Organization (WHO) endorsed the global plan of action on workers' health for the period 2008-2017 which makes the WHO in concert with the ILO. This action urges member states of the WHO towards the prevention, protection, and promotion of workers' health, to put emphasis on workplace and employers' roles, evidence for action and practice, and policy development and implementation [2]. It is clear that both United Nations agencies recognize critical issues concerning workers' health and work disability in general.

The International Classification of Functioning, Disability and Health (ICF) which was approved by the World Health Assembly in 2001 [3] is a universal conceptual framework and classification system which was intended by the WHO to describe and understand the different components of functioning of a person given a health condition. We will use the ICF framework to argue the need for a conceptual definition of vocational rehabilitation (VR) within the context of work disability and participation in general.

\section{Burden of Work Disability}

People with disability participate less in the labour market than those without disability. In the European Union specifically, the number of people with disability who had employment was $22.3 \%$ less than those without disability [4]. The impact of work disability is evident not just at the person-level (lack of satisfaction, inability to cope, or loss of income) but is also its socioeconomic impact which may involve lost work productivity and increased healthcare expenses. Additional burden is on families and caregivers, and on co-workers who need to take on additional responsibilities $[5,6]$. To address this burden, work disability management is essential.

The process of VR can be seen as a component of the overarching disability management in this paper. Using the ICF framework, disability as an object of rehabilitation, is a term associated with impairments of body structures and body functions, activity limitations, or participation restriction [3]. Therefore, disability is the opposite of functioning and when taken in the context of work is work disability. This paper argues that disability management is broad and encompasses all sort of disabilities to include work disability. Williams and Westmorland in their literature review, looked at the shared goal of workplace disability management in particular and how return-to-work (RTW) can be facilitated [7]. An earlier review of Tate [8], also makes a link between work disability and RTW by looking at general disability context. It is work disability that is the object of VR or RTW strategies [9-12] but not necessarily to the exclusion of other socioeconomic outcomes $[13,14]$ that may be associated with VR.

Addressing work disability is multifaceted given the various factors around the worker that need to be considered. One key component of work disability is vocational rehabilitation (VR), which is sometimes referred to as occupational rehabilitation or work or workplace rehabilitation [15]. Simply put, VR is a process of engaging or re-engaging a person with work. Obviously, this definition is too simplistic and would not necessarily satisfy all stakeholders in VR. As far as we know, a comprehensive definition of VR that is consented upon is currently unavailable. To promote the global advancement of VR knowledge and practice, we need a common conceptual definition of VR in order to properly identify VR-related services and their scope to help us decide how workers can benefit from those services. Comparable data and outcomes require a common conceptual framework. It appears that the design and delivery of current VR services may not be underpinned by a universal well-accepted concept. Hence, the objective of this discussion paper is to offer a conceptual definition for VR which is not bound by local delivery models and can be shared globally. Our specific aims are: (1) to present the different essential elements in the conceptual definition of VR and (2) to present the benefits and interface of using the ICF in VR.

\section{Model Considerations for Defining VR}

There are models on disability depending on the theoretical underpinning: medical, social and environmental, and biopsychosocial models [16-18]; each of which could be an attribute of VR-specific models briefly reviewed below. We recognize that VR-specific models could not be ignored as they play a complementary role along with the ICF, in explaining the full lived experience of patients or clients participating in a VR program. We know that there are a number of frameworks reported in the return-to-work (RTW) and work disability literature that have conceptualized or described the RTW process with important implication to VR [19-21].

Predating the ICF, Feuerstein presented a work disability model that looks at the biopsychosocial factors around work (re-)participation from medical condition to 
psycho-physical characteristic and work demand that determine RTW [22]. Loisel and colleagues published the Sherbrook Model in 1994, a multidisciplinary, comprehensive and operational model which has demonstrated utility in the management of occupational back pain [19], and from which adaptations to the model have been made to illustrate the multidisciplinarity and biopsychosocial approach in RTW interventions [23-25]. In 2005, RTW has been conceptualized as a continuum of events from being "off work", "re-entry", "retention", and "advancement" [26]. Different studies have also emphasized the importance of psychosocial factors, looking at individual motivation and behavior for RTW to gauge intervention [20, 27, 28].

Some models are also profession-dependent i.e. in which profession the model is being commonly used or based on which a clinical-decision making is being made [29], the Kielhofner's model on human occupation [30] in occupational therapy and Engel's biopsychosocial model [17] in biomedicine, for instance. Different countries have different socioeconomic and political settings which also would mean different custom-fit models of application in RTW services and workers' compensation [4].

Vocation-specific models, showing adequate evidence, and which may be used to support and aid this especially vulnerable group with cognitive problems to attempt to return to work, are the case coordination model the resource facilitation model and the individual placement and support model [31-33].

Pransky and colleagues well noted that a research and practice model is needed to serve the multiple players, priorities, and stakeholders in RTW [34]. Given the diversity of VR and RTW, a model that covers all possible factors may not be realistic although quite ideal. Instead, we may need a guiding framework that is just as integrative, dynamic, and interactive as RTW itself with consideration for the biosychosocial aspects of rehabilitation [14].

In 2007, Schultz and colleagues published a critical review of models on work disability and RTW [13]. In their conceptual review, wide ranging perspectives were found on which dimension of health is being investigated and whether the focus of the model is on the systems as a whole or the individual worker [13]. Further, the author states that RTW requires a "more precise definition of function" [13]. The ICF has the ingredients offering a precise definition of function for VR. Besides, it satisfies what would be an RTW model as suggested by Schultz and colleagues: multivariable, parsimonious, and generalizable.

\section{Providing a Definition of VR}

An ICF-based definition of "rehabilitation" has been presented as a "health strategy that [is] based on the WHO's integrative model of human functioning and disability [which] aims to enable people with health conditions experiencing or likely to experience disability, to achieve and maintain optimal functioning in interaction with the environment [35]." Considering "rehabilitation" as a key word and starting point, we believe that this same principle for the definition can be applied in the context of vocation or work that is VR.

The first step is developing a definition based on a unifying model in VR that is not intended to be specific to a certain vocation, provider, country, etc., then from this generic model, a more specific model may be developed to suite specific needs. VR-specific models, if used along with the ICF, can be useful in understanding the most significant aspects of VR and work disability in general. VR has been defined in many ways depending on the perspective. It is tempting to propose a precise definition from each perspective but because of the diversity of VR as a field, it might be preferable to provide the broadest definition possible which could then be operationalized in specific settings. A definition which seems comprehensive at a first glance refers to VR as "medical, psychological, social and occupational activities aiming to re-establish among sick or injured people with previous work history, their working capacity and prerequisites for returning to the labour market" [36]. However, the definition excludes those who have never worked or have had minimal or sporadic work experiences [37]. For example, many young people in unfavourable economic situations may find it extremely difficult to enter the labour market to begin with and those with developmental disabilities in particular may find it even harder. Both groups may not have work experience at all and may also benefit from VR. Therefore, including "entry" into the labour force through VR may be important to consider when defining VR. In a way, VR might be an old term for what nowadays would be called return to work (RTW) after illness or injury, or work (re-)integration for workers with activity limitations [38]. However, looking at the process of RTW, from a purpose and problem-based point of view, VR may be similar to work or workplace rehabilitation or occupational rehabilitation [15]. Hence, the term VR will be used in this paper as the overall construct.

From a societal context, VR is designed to maximize work participation of persons with disabilities and to promote their full integration and participation in the society [39]. VR involves the processes by which services improve a person's capacity for work, help them return to work or assume work duties at a permanent and sustainable level. These processes are subject to explanation and evaluation. Vocational rehabilitation can also be seen as an outcome oriented intervention, subject to evaluation by Randomized Controlled Trials and longitudinal evaluation. 
Consequently, the outcome measures of such an intervention are important to consider, not in terms of a dichotomy (on/off work) but within the continuum of work participation-from not working or working in sheltered environments to full time regular duty. Hence, the full scope of work participation is important to consider $[26,40]$.

A definition should include the aim of VR to help people participate in working life, either because they carry an elevated risk to suffer from impairment in working life (secondary prevention) or to help them cope with impairments in their work participation (tertiary prevention). Accordingly, VR must have in its definition a consideration for all kinds of diseases or disabilities, and all kinds of interventions and approaches that are relevant towards participation in working life.

VR should be worker (or client/patient)-centered and should be based on current evidence, which is delivered jointly by health professionals (such as physicians, occupational therapists, physiotherapists, and nurses), nonhealth related professionals (such as case managers, rehabilitation counsellors, and job coaches in some areas; insurers, home caregivers, etc.). This VR intervention is dynamic in that, until an optimal and sustainable outcome can be achieved, there may also be one or more professionals involved, working concurrently and collaboratively or alone but in communication with other stakeholders such as employers and work supervisors. Depending on jurisdiction and social security conditions, various disciplines will be involved in VR who will operate at the interface of work and health care. Any discipline-based definition would easily exclude large groups of professionals involved in some countries but not in all.

VR has a wide number of stakeholders including workers, health and non-health professionals, health organizations, insurers, representatives of the social security and labour system, family, employer or work supervisor. VR, similar to other fields of practice, consists of an assessment that identifies problems and relevant factors and proposes consequent intervention which may be followed by a re-assessment. Assessments may involve the worker, the job, workplace, performance, environment, and community in some instances. For example, part of the assessment may include identifying the job demands and evaluating potential barriers (e.g. environmental barriers in the ICF). Environment-based assessments could include worksite assessments, job analyses, work-study, personal relations at work, health and safety and travel to work.

VR provides services or programs that are funded and organized with the explicit aim of enabling work participation for persons with work-related disability. The services can be located in a range of environments or among different service settings. VR could consist of services by a range of specialists who have training or experience related to working, workplaces, labour market, and health conditions, as well as activity and participation as they relate to work and employment. As a holistic process, VR providers can be based in traditional healthcare settings (e.g., clinics, hospitals) or those outside these traditional settings such as those in the community (e.g., work placement). VR or related services may be publicly available (provided or coordinated by government agencies) or it can also be provided by private healthcare organizations or outpatient clinics [41, 42], or non-profit organizations. Delivery of VR services can depend on a variety of resources such as equipment, standardized measures (self-report or objective outcome measures), and human resources, such as enlisting natural supports.

VR services are based on individual needs and defined as resources or services a person might need to be employable or to be employed, such as assistive technology devices and counselling and skills development services (e.g. products and technology, services, systems and policies as specified in the ICF). For instance, a person with blindness will need screen reading software to access a computer and people with a cognitive or mental disability might need a talking electronic reminder device programmed to prompt them when it is time to perform certain tasks. In the area of intellectual disability, VR assessment may involve addressing work attitudes and qualification skills into the "job world". People who have limited work histories or have experienced lengthy marginalization from the workforce in particular need ongoing services for supported employment. Services that may be considered as "ongoing" include addressing emotional stability, human relations, motivation for work, psychosocial factors, learning a range of work-related skills, and developing job accommodations [43].

As an illustrative example, the US Core Council of Rehabilitation Education (CORE) which is charged to accredit academic programs in professional rehabilitation counselling, includes in its standards competencies and functions related to VR such as disability benefits and workers' compensation system, work analysis and modification, job counselling, work conditioning, work environment, placement, and assistive technology in government and private and community-based VR programs [44]. This effort to standardize by CORE is consistent with published literature in VR.

In summary, there are five elements that are essential based on the discussion above and should be considered in a conceptual definition of VR (Fig. 1).

\section{Conceptualizing VR Using the ICF Interface}

The ICF, in order to describe functioning and disability, consists of components that include body structure and 
Fig. 1 Essential elements towards a conceptual definition of VR
1. Focus on engagement or re-engagement to work as outcome

2. Along a work continuum (time, phase)

3. Involving various health conditions or events (impairment, limitation or restriction) leading to work disability

4. Patient-centered and evidence-based

5. Multi-professional or multidisciplinary intervention body functions at the body level, and activities and participation at the community/society level. Functioning and disability as embodied in the ICF also consider the influence of contextual factors such as those related to the person and those related to the environment, on functioning. Therefore, functioning is a result of the interplay between and among these components.

The ICF offers a valuable framework for conceptualizing work disability and VR. It is broad in its application and conceptually generic. While this may be a challenge when it comes to specific VR settings, the ICF can be adapted to specific uses and purposes in VR. The ICF also covers the widest possible set of factors that may affect a person with a health condition. Being able to capture and consequently code for "functioning" or the lived experience of the person is fundamental to the ICF. The ICF is not limited to the person's culture, region, or health condition [3]. With these benefits, the ICF can be conceptually useful to integrate a comprehensive picture of the person and the various factors involved in VR and the work (re-) entry process.

Given its benefits, limitations of the ICF and concerns related to its use have also been identified. For example, critics have argued that the classification requires further operational definition if it is to be useful in practice [45]. The ICF was commented as created from the perspective of "experts" and lacks the intersubjectivity of the lived experience of disability [46]. The ICF may be too broad which makes the operationalization of its categories difficult or less precise. In the context of VR, while providing a comprehensive list of domains, the ICF cannot be directly linked to concepts like work status, work productivity, work ability, and job type. The ICF does not currently provide specific categories for personal factors- which is an essential component in VR. Perhaps most troublesome is the concern that the ICF sustains an individual view of deviance from the norm, that compromises full access to basic rights of citizenship such as employment [47]. Development of conceptual clarity for and demonstration of the applicability of ICF is deemed useful for linking the ICF model to VR practices.

Within the ICF framework, VR may refer to a specific form of interventions that are primarily aimed to assist a person who has impaired, limited, or restricted work functioning while considering contextual factors such as

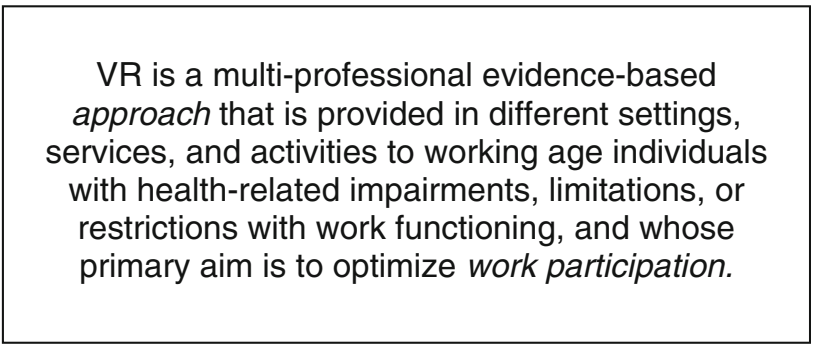

Fig. 2 Proposed conceptual definition of VR based on the ICF

personal and environmental factors to achieve optimal work participation (Fig. 2). The proposed conceptual definition supports a broad scope of services delivered and clientele served. For example, the definition is consistent with serving those whose work participation might be classed as "return to work" as well as those who are at risk in relation to making the transition to adult employment and those who are marginalized from employment. It encompasses a broad range of health conditions that have been associated with significant disruptions in work participation. It is noteworthy that under the conceptual definition there are differences across countries in how VR is structured and operationalized but there appears to be a common understanding of VR as focusing on achieving optimal work participation. For example, a comparison of the US and Sweden vocational rehabilitation systems, highlight the extent to which VR in the former is operationalized as a social service, in comparison to the more medical oriented service of the latter [48] but altogether shares the same purpose of RTW.

\section{How is the ICF Compatible with Vocational Rehabilitation?}

In our opinion, the ICF and VR-specific models complement each other. Many articles have been published supporting this ICF interface [26, 40, 49-53]. The work of Wasiak and colleagues used the ICF to examine time-based RTW outcomes employing the contextual factors around the person and the environment. They further suggest that the inconsistency in outcome measures in RTW could be addressed by following a common framework [50]. 
Recently, Young used the ICF to code for personal and environmental factors that may facilitate sustained RTW and inform intervention [49]. The most elaborate work so far has been published by Sandqvist and Henriksson in 2004 explicitly conceptualizing the assessment of work functioning to include body, individual, and society. Their conceptual framework also integrated the ICF contextual factors that influence work functioning over time [40]. Given these notable works, we do not see conflicting roles between the ICF and other VR or work disability-specific models. Moreover, the advantage of defining VR within the ICF is that it makes use of existing and common language which is consented upon and embedded in the WHO.

\section{Where do We Go from Here?}

A common understanding of VR and its operationalization will allow better communication with the stakeholders and will guide interventions provided within the scope of VR. Consequently, this understanding would lead to better management model for service delivery which maintains or improves the functioning of a person with disability within the context of employment. A shared conceptual definition will also benefit the ongoing dialogue about the meaning of VR and its many elements, preventing confusion among stakeholders, including workers. Moreover, an acceptable conceptual definition would provide a platform for legislation, professional development for VR practitioners, and reimbursement.

In our opinion, the ICF makes an innovative contribution to practice and research in VR by including the functioning and disability perspective, rather than the traditional biomedical or disease perspective alone. It is our hope that this paper will stimulate and encourage further discussion and dialogue at a global level.

The ICF's conceptual framework is built upon a biopsychosocial and integrative model that helps us better understand the full scope of the lived experience of individuals in a VR program and the impact of health conditions on work functioning. The ICF, as a classification system, has code numbers, which are universal key words to be used in evaluation of individuals receiving VR services. Each country has a different language and its citizens have varying ranges of experiences, but an ICF code will unify them into comparable data that could be used to assess VR outcomes internationally. We therefore propose that the ICF be used to further develop advancements in the VR field.

VR applies and integrates work participation-relevant approaches in partnership between the person and the VR service provider and in appreciation of the person's perception of his or her position in life and among different settings including hospitals, rehabilitation facilities, workplace, and community, as well as across different sectors, including health, education, labor, and social services, systems, and policies - all of which are embodied in the ICF. VR as an operationalization of rehabilitative strategy is anchored in enabling persons with work disability who are experiencing or are likely to experience problems in achieving and maintaining optimal vocational functioning and work participation. This definition is consistent with VR concepts of empowerment, including the critical role that patients have in working as partners in the process. Our conceptual definition not only highlights the importance of maximizing capacity and strengthening resources, but also of providing a facilitative environment. It stresses the need for VR providers to look at the interaction between the work ability and the environment to determine if VR interventions will best be directed toward the client, the environment, or both. This conceptual relationship is consistent with the ICF-based definition of a rehabilitation strategy [35].

\section{Challenges}

There are clear benefits to using the ICF within the VR context, although we also recognize the challenge that is ahead of us-namely the direct and precise application of the ICF in specific VR settings. We propose that the ICF and VR interface be explored further using empirical and qualitative studies and encouraging stakeholders' participation.

The lack of classification of personal factors of the ICF may point to efforts that must be undertaken in the future to further understand their impact on work participation. Moreover, the operationalization of environmental factors could be challenging, especially considering the breadth of these factors in the workplace and around the worker. Hence, we suggest carefully investigating the role of contextual factors (personal and environment) in capturing important aspects of work functioning.

Different perspectives can be found that shape the understanding and practice of VR [54] therefore, an ideal definition should be "overarching" of these perspectives. We recognize that these differences in terms depend on the perspective. For example, VR as a term may not fit well in the broad area of economic development. VR has historically focused on the person as the source of problems in employment, while economic development perspectives have developed the idea that people who are routinely marginalized from employment are likely to undergo system-level disadvantages. An inclusive conceptual definition serves as a powerful organizing force that could help unite the diverse stakeholders of the VR field, and by 
combining their knowledge and experience, advance the mission of enabling employment and re-employment of persons with disability.

Acknowledgments The authors would like to thank Debra Homa (Department of Rehabilitation and Counseling, University of Wisconsin-Stout, Menomonie WI, USA), Eva Schonstein (Medibank Health Solutions and The University of Sydney, Sydney, Australia), Urban Studer (Schweizerische Bundesbahnen SBB, Bern, Switzerland), and Jos Verbeek (Finnish Institute of Occupational Health, Kuopio, Finland) for serving as reviewers of the manuscript prior to submission. We also would like to thank the other members of the International Work Rehabilitation Network (i-NetWork) for their active participation during the conference on the ICF Core Set Development for Vocational Rehabilitation: Alex Burdorf (The Netherlands), Tania Buys (South Africa), Jain Holmes (UK), Stefan Koch (Germany), Jan Kool (Switzerland), Dennis Nowak (Germany), Rahel Oertli (Switzerland), Soo-Kyung Park (South Korea), Robin Pickard (UK), Stefan Staubli (Switzerland), and Frank Staudenmann (Switzerland). i-NetWork is an informal network of researchers, practitioners, and advocates whose interest is to advance the field of work rehabilitation. Special thanks to Monika Finger and Miriam Lückenkemper for reviewing the manuscript prior to submission.

\section{References}

1. International Labour Organization. About the ILO. Available from: http://www.ilo.org/global/About_the_ILO/lang-en/index.htm. 2010.

2. World Health Organization. Workers' health: global plan of action. 60th World Assembly. WHA60.26. 2007.

3. World Health Organization. International Classification of Functioning, Disability, and Health: ICF. Geneva, Switzerland; 2001.

4. Gobelet C, Franchignoni F. Vocational rehabilitation. Paris: Springer; 2006.

5. Ellenbogen PS, Meade MA, Jackson MN, Barrett K. The impact of spinal cord injury on the employment of family caregivers. J Vocat Rehabil. 2006;25(1):35-44.

6. Boden LI. Running on empty: families, time, and workplace injuries. Am J Public Health. 2005;95(11):1894-7.

7. Williams RM, Westmorland M. Perspectives on workplace disability management: a review of the literature. Work. 2002;19(1): 87-93.

8. Tate DG. Workers' disability and return to work. Am J Phys Med Rehabil. 1992;71(2):92-6.

9. Kuoppala J, Lamminpaa A. Rehabilitation and work ability: a systematic literature review. J Rehabil Med. 2008;40(10): 796-804.

10. Straaton KV, Fine PR. Addressing work disability through vocational rehabilitation services. Bull Rheum Dis. 1997;46(3): $1-3$.

11. Shrey DE. Worksite disability management model for effective return-to-work planning. Occup Med. 2000;15(4):789-801.

12. Briand C, Durand MJ, St-Arnaud L, Corbiere M. How well do return-to-work interventions for musculoskeletal conditions address the multicausality of work disability? J Occup Rehabil. 2008;18(2):207-17.

13. Schultz IZ, Stowell AW, Feuerstein M, Gatchel RJ. Models of return to work for musculoskeletal disorders. J Occup Rehabil. 2007;17(2):327-52.

14. Schultz IZ. Disentangling the disability quagmire in psychological injury: part 1- disability and return to work: theories, methods, and applications. Psychol Inj and Law. 2008;1:94-102.
15. Escorpizo R, Ekholm J, Gmunder HP, Cieza A, Kostanjsek N, Stucki G. Developing a core set to describe functioning in vocational rehabilitation using the international classification of functioning, disability, and health (ICF). J Occup Rehabil. 2010;20(4):502-11.

16. Peterson DB. Psychological aspects of functioning, disability, and health. New York, NY: Springer Publishing Company; 2011.

17. Engel GL. The need for a new medical model: a challenge for biomedicine. Science. 1977;196(4286):129-36.

18. Peterson DB. International classification of functioning, disability and health (ICF): an introduction for rehabilitation psychologists. Rehabil Psychol. 2005;50:105-12.

19. Loisel P, Durand P, Abenhaim L, Gosselin L, Simard R, Turcotte J, et al. Management of occupational back pain: the Sherbrooke model. Results of a pilot and feasibility study. Occup Environ Med. 1994;51(9):597-602.

20. Franche RL, Krause N. Readiness for return to work following injury or illness: conceptualizing the interpersonal impact of health care, workplace, and insurance factors. J Occup Rehabil. 2002;12(4):233-56.

21. Schultz IZ, Crook J, Meloche GR, Berkowitz J, Milner R, Zuberbier OA, et al. Psychosocial factors predictive of occupational low back disability: towards development of a return-to-work model. Pain. 2004;107(1-2):77-85.

22. Feuerstein M. A multidisciplinary approach to prevention, evaluation, and management of work disability. J Occup Rehabil. 1991;1(1):5-12.

23. Lambeek LC, van Mechelen W, Knol DL, Loisel P, Anema JR. Randomised controlled trial of integrated care to reduce disability from chronic low back pain in working and private life. BMJ. 2010;340:c1035.

24. Anema JR, Steenstra IA, Bongers PM, de Vet HC, Knol DL, Loisel P, et al. Multidisciplinary rehabilitation for subacute low back pain: graded activity or workplace intervention or both? A randomized controlled trial. Spine. 2007;32(3):291-300.

25. Steenstra IA, Anema JR, van Tulder MW, Bongers PM, de Vet $\mathrm{HC}$, van Mechelen W. Economic evaluation of a multi-stage return to work program for workers on sick-leave due to low back pain. J Occup Rehabil. 2006;16(4):557-78.

26. Young AE, Roessler RT, Wasiak R, McPherson KM, van Poppel MN, Anema JR. A developmental conceptualization of return to work. J Occup Rehabil. 2005;15(4):557-68.

27. Xu YW, Chan CC, Lam CS, Li-Tsang CW, Lo-Hui KY, Gatchel RJ. Rehabilitation of injured workers with chronic pain: a stage of change phenomenon. J Occup Rehabil. 2007;17(4):727-42.

28. Li-Tsang WPC, Chan HHK, Lam CS, Lo-Hui KYL, Chan CCH. Psychosocial aspects of injured workers' returning to work (RTW) in Hong Kong. J Occup Rehabil. 2006;17:279-88.

29. Holmes J. Vocational rehabilitation. Oxford, UK: Blackwell Publishing; 2007.

30. Kielhofner G, Burke JP. A model of human occupation, part 1. Conceptual framework and content. Am J Occup Ther. 1980; 34(9):572-81.

31. Fadyl JK, McPherson KM. Approaches to vocational rehabilitation after traumatic brain injury: a review of the evidence. J Head Trauma Rehabil. 2009;24(3):195-212.

32. Trexler LE, Trexler LC, Malec JF, Klyce D, Parrott D. Prospective randomized controlled trial of resource facilitation on community participation and vocational outcome following brain injury. J Head Trauma Rehabil. 2010;25(6):440-6.

33. Bond GR. Supported employment: evidence for an evidencebased practice. Psychiatr Rehabil J. 2004;27(4):345-59.

34. Pransky G, Gatchel R, Linton SJ, Loisel P. Improving return to work research. J Occup Rehabil. 2005;15(4):453-7.

35. Stucki G, Cieza A, Melvin J. The International classification of functioning, disability and health (ICF): a unifying model for the 
conceptual description of the rehabilitation strategy. J Rehabil Med. 2007;39(4):279-85.

36. Selander J. Unemployed sick-leavers and vocational rehabilitation - a person-level study based on a national social insurance material; $\mathrm{PhD}$ thesis, Karolinska Institutet, Department of Rehabbilitation Medicine, Stockholm, Sweden. 1999.

37. Marnetoft S-U. The Challenges of Vocational Rehabilitation in Sweden. Kuntoutus Fin J Rehabil. 2009;4:5-10

38. Verbeek JH. How can doctors help their patients to return to work? PLoS Med. 2006;3(3):e88.

39. Parker RM, Szymanski EM, Patterson JB. editors. Rehabilitation counseling: basics and beyond. 4th ed. Austin: Pro-Ed; 2005.

40. Sandqvist JL, Henriksson CM. Work functioning: a conceptual framework. Work. 2004;23(2):147-57.

41. MacDonald-Wilson K, Rogers ES, Anthony WA. Unique issues in assessing work function among individuals with psychiatric disabilities. J Occup Rehabil. 2001;11(3):217-32.

42. Maronner J, Gandolfo C, Gold M, Hoff D. If you think work is bad for people with mental illness, then try poverty, unemployment, and social isolation. Psychiatr Rehabil J. 2000;23(2): 187-93.

43. Suzuki Y, Kikuchi E, Watanabe S. Assessment of vocational opportunities and continuing job placement for persons with mental disabilities: factors indicating levels of necessary support. Work. 2008;30(2):185-94.

44. Council on Rehabilitation Education. Revised core accreditation standards. Section II CORE accreditation manual. 2010;1-21.

45. Imrie R. Demystifying disability: a review of the international classification of functioning, disability and health. Soc Health Illn. 2004;26(3):287-305.
46. Borell L, Asaba E, Rosenberg L, Schult ML, Townsend E. Exploring experiences of "participation" among individuals living with chronic pain. Scand J Occup Ther. 2006;13(2):76-85.

47. Whalley-Hammell K. Deviating from the norm: a skeptical interrogation of the classificatory practices of the ICF. Br J Occup Ther. 2004;67(9):408-11.

48. Stubbs J, Deaner G. When considering vocational rehabilitation: describing and comparing the Swedish and American systems and professions. Work. 2005;24(3):239-49.

49. Young AE. Return to work following disabling occupational injury - facilitators of employment continuation. Scand J Work Environ Health. 2010;36(6):473-83.

50. Wasiak R, Young AE, Roessler RT, McPherson KM, van Poppel $\mathrm{MN}$, Anema JR. Measuring return to work. J Occup Rehabil. 2007; 17(4):766-81.

51. Lagerveld SE, Bultmann U, Franche RL, van Dijk FJ, Vlasveld MC, van der Feltz-Cornelis CM, et al. Factors associated with work participation and work functioning in depressed workers: a systematic review. J Occup Rehabil. 2010;20(3):275-92.

52. Sanderson K, Nicholson J, Graves N, Tilse E, Oldenburg B. Mental health in the workplace: using the ICF to model the prospective associations between symptoms, activities, participation and environmental factors. Disabil Rehabil. 2008;30(17): 1289-97.

53. Heerkens Y, Engels J, Kuiper C, Van der Gulden J, Oostendorp $\mathrm{R}$. The use of the ICF to describe work related factors influencing the health of employees. Disabil Rehabil. 2004;26(17):1060-6.

54. Kirsh B, Krupa T, Cockburn L, Gewurtz R. A Canadian model of work integration for persons with mental illnesses. Disabil Rehabil. 2010;32(22):1833-46. 